\title{
Dynamic Characteristics of Lifting Pipe on a Retrofitted Mining Vessel
}

\section{Fei Duan, Yuliang Liu}

Changjiang Institute of Survey, Planning, Design and Research, Wuhan 430010, Hubei, China DOI: $10.32629 /$ aes.v2i4.590

\begin{abstract}
Lifting pipe used in deep ocean mining is the tool to transport mineral from seabed to vessel. In this study, a vessel was retrofitted as an experimental ship for deep ocean mining with a U-type lifting pipe installed on the right side of vessel. Assuming pipe as a rigid structure, the impact of pipe on movements of vessel were discussed based on frequency domain method for hydrodynamic analysis.

Keywords: deep ocean mining, lifting pipe, dynamic response, fatigue
\end{abstract}

\section{Introduction}

Deep ocean mining is mineral retrieval process that take place on the ocean floor. Deep ocean mining system, which is used for mineral mining in the sea, includes mining support vessel, lifting system and seafloor mining tool, as shown in Figure 1. As one of the most important parts for deep ocean mining system, lifting pipe is applied to transports polymetallic nodule from seabed to vessel, undertaking various loads caused by wave, current, ship motion, gravity and so on.

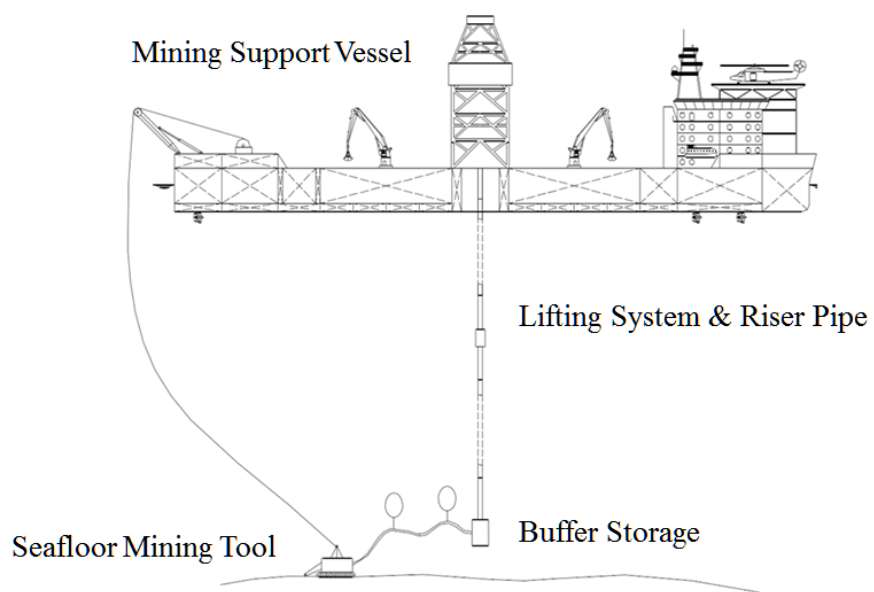

Figure 1. Deep ocean mining system

Although many studies have been done, for most analysis on deep ocean mining, the ship motion was always simplified as period motion in vertical direction and uniform velocity in direction of forward motion. (Wang et al.,2012; Li et al., 2007; Wang et al.,2005) In reality, the top end of lifting pipe is connected to vessel, whose motion is couple up to environment condition. These simple methods just take heave and navigational speed into consideration, ignoring other degrees freedom motion. Moreover, the ship motion is sensitive to the parameters of riser pipe, including length, diameter and so on. (Tahar et al.,2003; Kim et al., 2005) So, to obtain accuracy motion of mining support vessel and external loads on lifting pipe, vessel and lifting pipe should be coupled to analyze motion and loads on pipe.

In this regard, this paper presents the dynamic characteristic of the lifting pipe from hydrodynamic and structure aspect. The study subject is a sea trial system for deep ocean mining, whose lifting pipe was installed in the side of the experiment vessel. The vessel and lifting pipe coupled dynamic analysis was carried out to study effects of pipe on vessel motion. Potential theory is used for motion of vessel and Morison equation is applied for lifting pipe. Then a nonlinear structure analysis of lifting pipe was conducted using Morison equation and concentrated mass method for studying environment force. The nonlinear static configuration was used as an initial condition for this analysis and movement history of ship was applied as boundary condition of pipe top. Finally, the fatigue life of the connection joint between vessel and pipe is predicted. An effective method is proposed to decrease fatigue damage of the structure. 


\section{Model of deep ocean mining ship and environment}

\subsection{Sea trial system introduction}

Before commercial application, sea trial is indispensable to guarantee safety and feasibility for offshore structure. A sea trial system for deep ocean mining is shown in Figure 2. The experiment vessel is remolded from a deck ship, which a platform is added on starboard for connecting lifting pipe and vessel. The lifting pipe is "U" type with slurry filled in. The top end of pipe is connected to the side platform via flange and the bottom end of the pipe is free in ocean, which is $500 \mathrm{~m}$ far away from sea surface. A pump is configured on the lifting pipe I below $200 \mathrm{~m}$ of the sea surface for offering power of transporting slurry. For simple description, the connections between pipe and platform are defined as joint A and joint B.

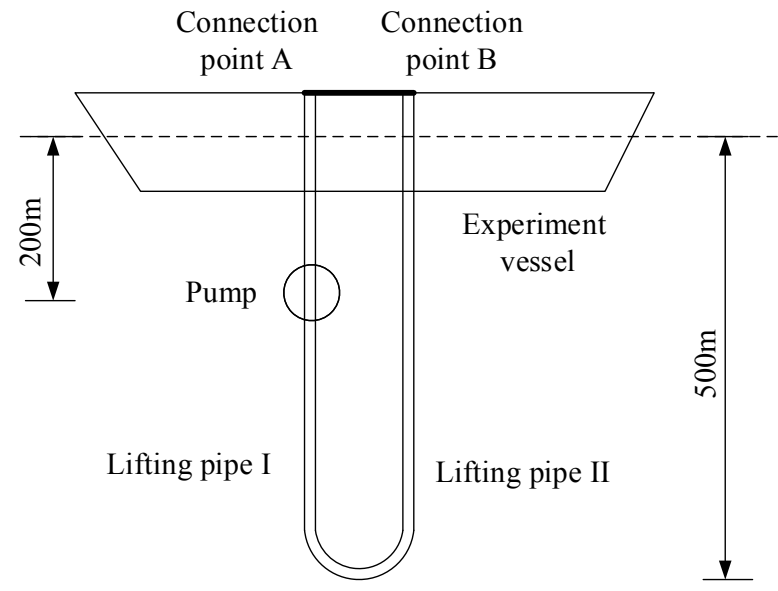

Figure 2. Sea trial system for deep ocean mining

The pipe is made of high strength steel (P110 API SPEC 5CT) and yield strength is 758MPa. The detail geometry parameter of pipe is shown as Table 1 and the summary parameter is shown as Table 2.

Table 1. Geometry parameter of lifting pipe

\begin{tabular}{cc}
\hline Outer diameter & $220 \mathrm{~mm}$ \\
\hline Wall thickness & $20 \mathrm{~mm}$ \\
Distance between two vertical pipes & $2 \mathrm{~m}$ \\
Weight of pump & $6000 \mathrm{~kg}$ \\
Density of slurry & $1133 \mathrm{~kg} / \mathrm{m}^{3}$ \\
\hline
\end{tabular}

Table 2. Principle dimensions of the experiment vessel

\begin{tabular}{cc}
\hline Displacement & $7757.2 \mathrm{t}$ \\
\hline Draft & $3.743 \mathrm{~m}$ \\
Height of center of gravity(CG) & $3.741 \mathrm{~m}$ \\
Distance of between midship and CG & $0.124 \mathrm{~m}$ \\
\hline
\end{tabular}

\subsection{Environment parameters}

Current is one of components which apply large environmental load on lifting pipe. Here, current profile is used for presenting current velocity related to depth of water. According to current statistical data, the current velocity of working sea area is shown as Figure 3. 


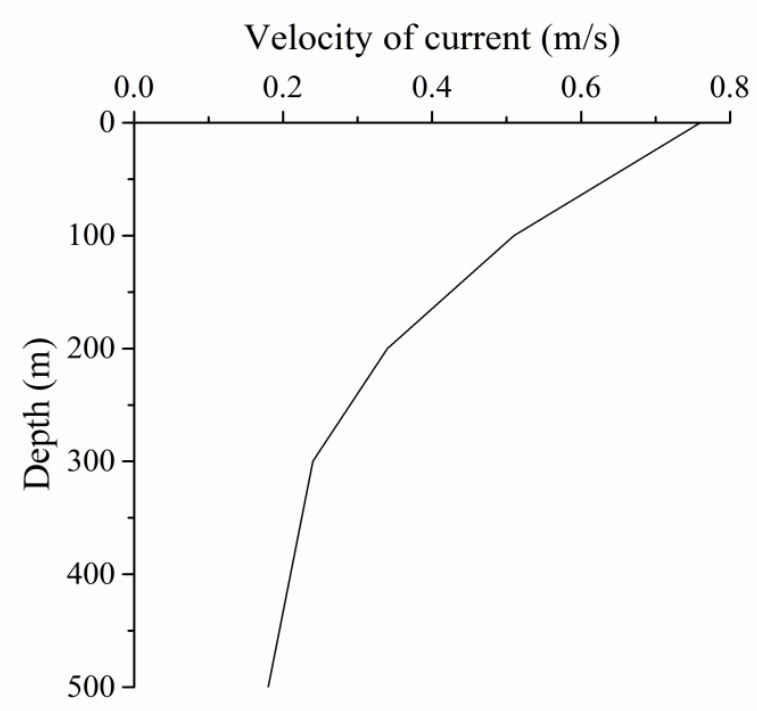

Figure 3. Current profile

The wave spectrum is always applied to estimate wave shape, which assumes that the wave can be described as a stationary random process (Faltinsen, 1993). For the fully developed sea conditions, the International Ship and Offshore Structure Congress(ISSC) recommended the use of the modified

Pierson-Moskowitz (P-M) wave spectrum (Bretschneider, 1968). The formula is presented by

$$
S_{P M}(\omega)=\frac{5}{16} \cdot H_{S}^{2} \omega_{p}^{4} \cdot \omega^{-5} \exp \left(-\frac{5}{4}\left(\frac{\omega}{\omega_{p}}\right)^{-4}\right)
$$

where

$\omega$ is angular frequency;

$\omega_{p}=2 \pi / T_{p}$ is the angular spectral peak frequency;

$H_{S}$ is significant wave height.

\section{Effect of lifting pipe on vessel motion}

For many floating structures, slender structure such as pipes and risers always are not considered when motion of floating structures is being calculated. (Liu et al., 2015; Liu et al., 2014) Because compensator installed on top of pipe can counteract part of vessel motion worked on pipe. For sea trial vessel, there is no compensator and pipe should be considered in the calculation of vessel motion.

\subsection{Hydrodynamic loads}

In ocean engineering, potential flow theory is widely applied to calculate hydrodynamic load of offshore structure assuming fluid is irrotational and incompressible. In this case, Laplace's equation is applicable for obtaining hydrodynamic load. But this method is inapplicable for slender structure in fluid because potential theory cannot consider viscidity of fluid, which is one of main load for slender structure in water. The resulting force on slender structure in ocean can be determined using Morison equation (Morison et.al., 1950), which is a combination of an inertial term and a drag form. Therefore, potential flow was applied for hydrodynamic load on hull and Morison equation was applied on lifting pipe.

Morison force acting on a slender structural member is

$$
d F=\frac{1}{2} \rho D C_{d}\left|u_{f}-u_{s}\right|\left(u_{f}-u_{s}\right)+\rho A\left(1+C_{a}\right) \dot{u}_{f}-\rho A C_{a} \dot{u}_{s}
$$

Where $D$ is characteristic drag diameter and $\rho$ is fluid density. $C_{d}$ and $C_{a}$ is drag coefficient and added mass coefficient respectively. $u_{f}$ and $\dot{u}_{f}$ is the transverse directional fluid particle velocity and acceleration respectively. $u_{s}$ and $\dot{u}_{s}$ is the transverse directional structure velocity and acceleration respectively. A is the cross-sectional area. The value of drag co- 
efficient and added mass coefficient are affected by several parameters including Re (Reynolds number), KC number (Keulegan-Carpente number) and others. These two hydrodynamic coefficients can be determined by experiments or previous studies. Here $C_{d}$ is selected as 1.2 and $C_{a}$ is selected as 1.0 according to previous study (Burrows, R., et al 1997).

\subsection{Frequency domain analysis}

Two models were used to study the effect of lifting pipe on ship motion by frequency domain analysis. The difference between these two models is lifting pipe. Other parameters, such as coordinate of gravity center, draft and initial place which can be changed by pipe, were same by adjusting by ballast water in different cabins. The analysis result is shown as below.

Figure 4 (a) shows roll response amplitude operator (RAO) of vessel with pipe and vessel without pipe in beam waves by frequency domain analysis. It is found that roll amplitude of vessel with pipe $(6.2 \% \mathrm{~m})$ became larger comprised to another model's roll amplitude $\left(3.55^{\circ} / \mathrm{m}\right)$. The peak caused by resonance in the Figure 4 (a) indicates roll natural period of vessel changes from $6.9 \mathrm{~s}$ to $13.8 \mathrm{~s}$ after equipping lifting pipe. It means lifting pipe installed in the side of ship can increase the amplitude of roll motion and enlarge the period of roll motion. Although large roll period is good for stability of roll motion, large roll amplitude can easily lead to accidents which may cause great wealth damage.

Figure 4 (b) shows the effect of lifting pipe on sway RAO when the ship is under beam waves. The motion features of these two models are different obviously from $7 \mathrm{~s}$ to $20 \mathrm{~s}$ of wave periods, especially from $12 \mathrm{~s}$ to $15 \mathrm{~s}$, sway amplitude of vessel without pipe increases slowly while the amplitude of vessel with pipe augments greatly from $0.6 \mathrm{~m} / \mathrm{m}$ to $1.1 \mathrm{~m} / \mathrm{m}$. Because the wave force on the lifting pipe also contributes to sway motion of vessel and this scope may be near natural period of sway motion. So, the difference is distinct in case of beam wave.

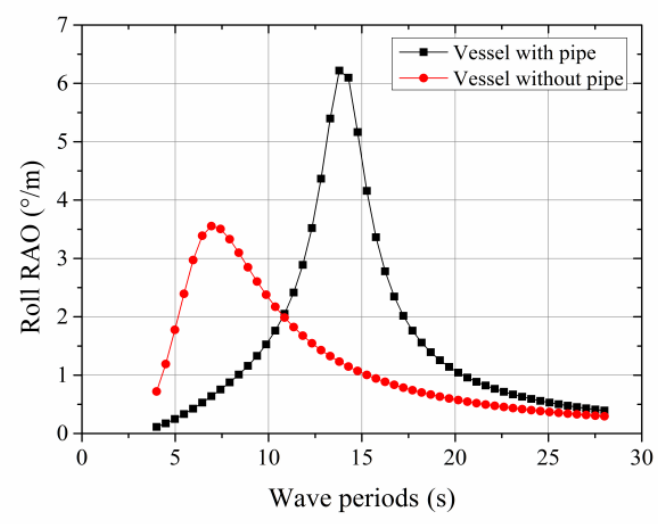

Roll motion

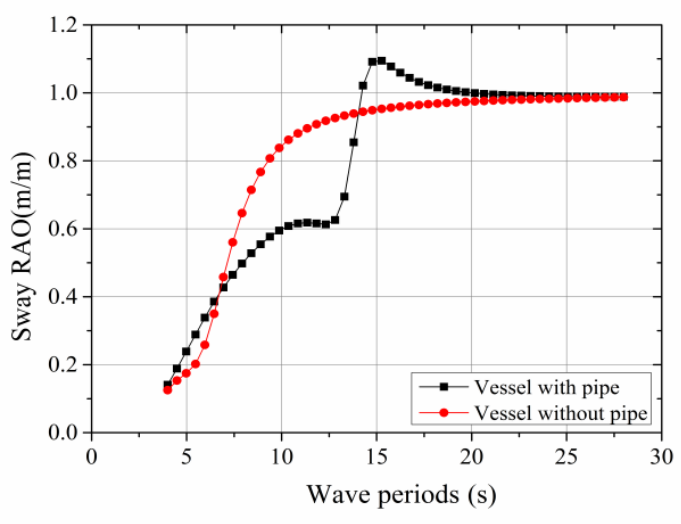

(b) Sway motion

Figure 4. Roll and sway RAOs of two models under beam waves

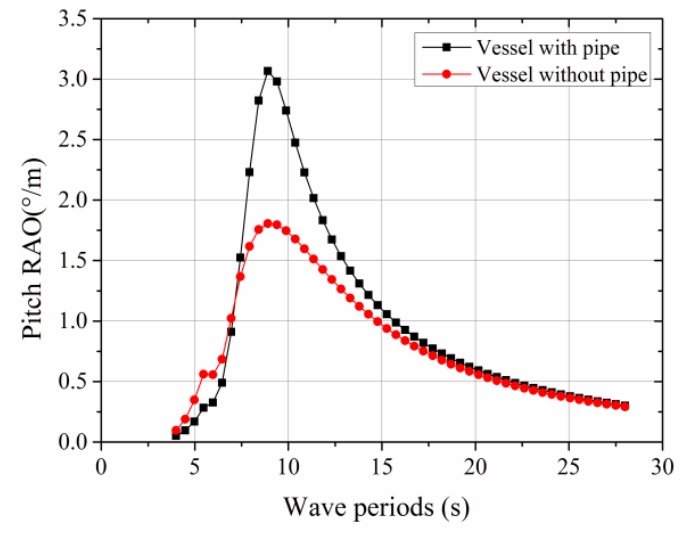

(a) Pitch motion

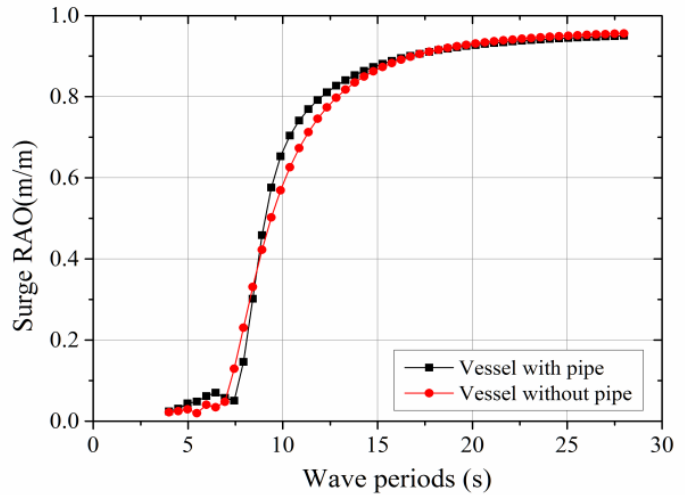

(b) Surge motion

Figure 5. Pitch and Surge RAOs of two models under head waves

In case of head waves, RAO of pitch motion changes greatly while RAO of surge motion varies slightly according to Figure 5. It is indicated that lifting pipe enlarge peak of pitch motion. But the natural period of pitch is almost same although 
lifting pipe is installed. (Figure 5(a)) And lifting pipe increases surge RAO slightly according to Figure 5(b). It means lifting pipe just has influence on maximum of pitch motion and makes little effect on natural periods of pitch and surge motion.

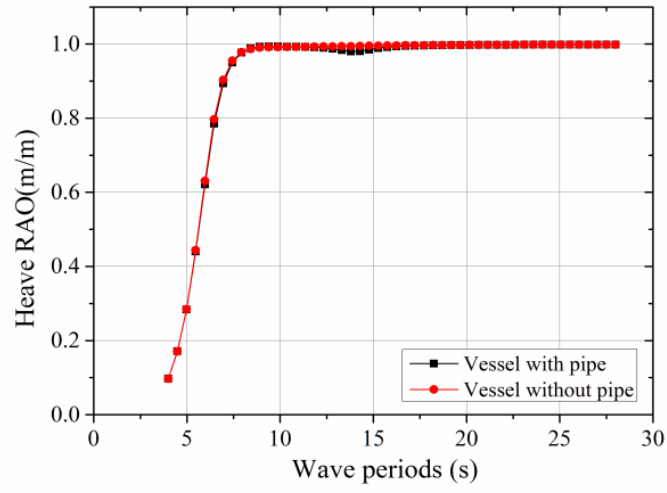

(a) Beam waves

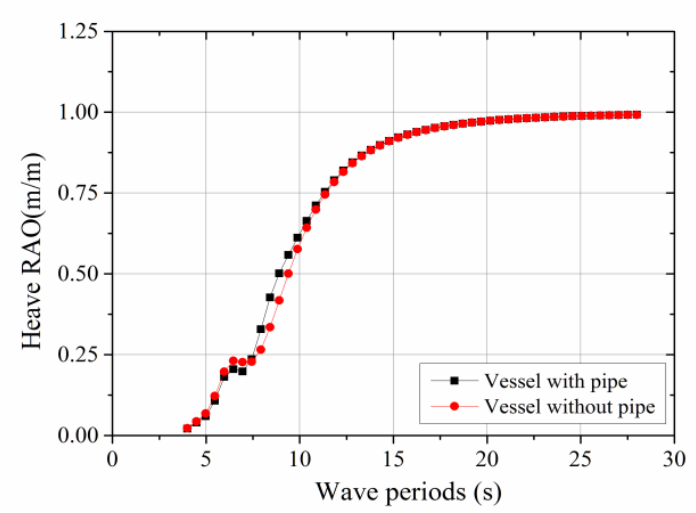

(b) Head waves

Figure 6. Heave motion of two models under beam waves and heave waves

Lifting pipe has no influence on heave motion. Figure 6 gives comparison of heave RAO of these two models under beam wave and head wave. The motion of vessel with pipe almost the same as motion of vessel without pipe. The reason why this case occurs is that Morison equation in AQWA only consider the wave force in normal direction and ignore wave force in tangential direction. But the tangential wave force here on pipe here is mainly generated by water viscosity which is small and ignorable compared to vertical force working on vessel.

\section{Conclusions}

Effect of lifting pipe installed on a retrofitted mining ship was studied in the view of movement in frequency domain and structural dynamic response in time domain. The conclusions obtained are as follows.

The lifting pipe installed on the side of vessel changes period of roll motion of vessel and amplify roll amplitude which may lead to risk. The lifting pipe has little influence on period of pitch motion, however, it aggravates pitch motion and makes amplitude lager. The change of heave motion can be neglected after pipe is installed for small change of water plane. Under head waves and beam waves, trends of sway and surge vary slightly after pipe was equipped.

\section{References}

[1] Wang, Z., Rao, Q. H., \& Liu, S. J. 2012. Fluid-solid interaction of resistance loss of flexible hose in deep ocean mining. Journal of Central South University, 19(11), 3188-3193.

[2] Li, Y., Liu, S., \& Li, L. 2007. Dynamic analysis of deep-ocean mining pipe system by discrete element method. China Ocean Engineering, 1, 014.

[3] Wang, G., \& Liu, S. 2005. Three-dimensional DEM model for deep-ocean mining pipe system. In Sixth ISOPE Ocean Mining Symposium. International Society of Offshore and Polar Engineers.

[4] Tahar, A., \& Kim, M. H. 2003. Hull/mooring/riser coupled dynamic analysis and sensitivity study of a tanker-based FPSO. Applied Ocean Research, 25(6), 367-382.

[5] Kim, M. H., Koo, B. J., Mercier, R. M., \& Ward, E. G. 2005. Vessel/mooring/riser coupled dynamic analysis of a turret-moored FPSO compared with OTRC experiment. Ocean Engineering, 32(14), 1780-1802. 